\title{
«Es un lector, no un orador»: sobre la tricotomía comunicación verbal, paraverbal y no verbal
}

\author{
“A Reader, Not a Speaker": On the Verbal, Paraverbal and Nonverbal Communication Trichotomy \\ “É um leitor, não um palestrante”: sobre a tricotomia comunicação verbal, paraverbal e não verbal
}

Susana Ridao Rodrigo* (http://orcid.org/0000-0002-1109-655X)

Departamento de Lengua Española y Lingüística General, Facultad de Letras, Universidad de Murcia, Murcia, España
Recibido: $04-10-16$

Revisado: $27-03-17$

Aceptado: $15-05-17$

Publicado: 11-06-17
RESUMEN. El presente artículo tiene como objetivo analizar la relevancia que asumen la comunicación verbal, paraverbal y no verbal para un grupo de estudiantes al observar y evaluar el discurso de un orador. El corpus analizado está compuesto por las anotaciones efectuadas por 30 alumnos sobre los déficits comunicativos que detectan en el discurso de un orador. Los resultados obtenidos indican que el $11.27 \%$ de tales críticas iban dirigidas a la comunicación verbal, el 30.82\% a la comunicación paraverbal y el $57.89 \%$ a la comunicación no verbal. Por tanto, estas conclusiones resultan afines con las alcanzadas por Mehrabian (1972), si bien difieren parcialmente de las presentadas en van-der Hofstadt (2005) u Orzáiz (2009). Se discuten las implicancias de estos resultados.
Palabras clave: transmisión del mensaje, comunicación verbal, comunicación paraverbal, comunicación no verbal, oratoria.

ABSTRACT. This paper aims to analyze the relevance of verbal, paraverbal and nonverbal communication for a group of students by observing and evaluating a speaker's speech. The corpus analyzed is composed of the notes made by 30 students about the communicative flaws detected in a speaker's speech. The results obtained indicate that $11.27 \%$ of such criticisms were aimed at verbal communication, $30.82 \%$ at paraverbal communication and $57.89 \%$ at nonverbal

Key words:

message transmission, verbal communication, paraverbal communication, 
communication. Therefore, these conclusions are similar to those reached by Mehrabian (1972), although they differ in part from the ones presented in van der Hofstadt (2005) or Orzáiz (2009). The implications of these results are discussed. nonverbal communication, public speech.
RESUM0. O presente artigo tem por objetivo analisar a relevância que assume a comunicação verbal, paraverbal e não verbal para um grupo de estudantes ao observar e avaliar o discurso de um palestrante. O corpus analisado é constituído por anotações feitas por 30 alunos sobre os déficits comunicativos detectados no discurso de um palestrante. Os resultados indicam que 11,27\% dessas críticas foram destinadas à comunicação verbal, 30,82\% à comunicação paraverbal e 57,89\% à comunicação não verbal. Portanto, estes resultados são semelhantes aos obtidos por Mehrabian (1972), embora parcialmente difiram dos apresentados em van-der Hofstadt (2005) ou Orzáiz (2009). As implicações dos presentes resultados são discutidos.

\author{
Palavras-chave: \\ transmissão \\ da mensagem, \\ comunicação \\ verbal, \\ comunicação \\ paraverbal, \\ comunicação não \\ verbal, oratória.
}

Ya desde la Edad Antigua tanto en la civilización griega como en la romana se demostró la importancia de la oratoria; un fiel reflejo de dicha preocupación lo constituyen los documentos destinados al incremento de la capacidad comunicativa del orador. Si bien es cierto que en tiempos remotos han existido escritos de esa naturaleza, es en la actualidad cuando han proliferado investigaciones de tal índole de manera muy acusada; hay autores -como Fernández García (2000)- que aseveran que este aumento de producción bibliográfica fundamentalmente se debe al rápido crecimiento que han vivido los medios de comunicación de masas en las últimas décadas. La relevancia de la comunicación pública reside en que el ser humano es muy sociable, hasta el punto de que dedica la atención, la capacidad y las expectativas a dicho fin (Laborda Gil, 2014). Del mismo modo, en estos momentos se asume que la promoción personal y profesional se consigue hablando bien en público, debido a que ser buen orador implica ser buen comunicador (Martínez Selva, 1994).

Existe un convencimiento generalizado de que la palabra articulada representa el más perfecto vehículo de nuestro pensamiento (Berlanga \& García, 2014). Más aún, sostiene Cattani (2010) que cuando las palabras cautivan al auditorio son calificadas como «mágicas», ya se entienda como una metáfora poética o como un argumento retórico; por ello, la comunicación ha de ser interpretada también como un cautivador medio de transmisión del conocimiento, habida cuenta de que «las palabras seducen, engañan, espolean, hechizan» (2010, p. 25). Desde otro ángulo, Hernández y García (2008) defienden que por sí sola la palabra no resulta elocuente, sino que la elocuencia está condicionada -en buena parte- por la figura del orador, su testimonio de vida, sus actitudes, sus gestos y sus expresiones faciales. 
El indiscutible denominador común existente en las pesquisas sobre oratoria lo conforma el anhelo de describir las características que ha de tener un buen orador. Para Laborda Gil (2014) estas cualidades se sustentan sobre cinco pilares básicos: (a) conocimiento del tema, (b) entrega a la audiencia, (c) calidad de la voz, (d) fluidez expresiva y (e) faceta del actor; en esta nómina hacen acto de presencia -aparte de la comunicación verbal-elementos vinculados con el paralenguaje y la comunicación no verbal. Ciertamente, «Es importante el qué se transmite, pero no menos importante resulta el cómo se hace ${ }^{1 » ~(B a l l e n a t o ~ P r i e t o, ~ 2013 b, ~ p . ~ 151) . ~}$

Las reflexiones sobre la dicotomía lengua oral y lengua escrita se remontan a los tiempos clásicos; así, Aristóteles (2001) observaba que la palabra hablada se presta más a la equivocidad, frente a una mayor precisión de la palabra escrita. La principal diferencia entre ambos planos comunicativos estriba en que un mensaje escrito es cifrado únicamente a través de la comunicación verbal; en oposición, en un discurso oral intervienen también -junto con la comunicación verbal- la comunicación paraverbal y la comunicación no verbal. Más de la mitad de los mensajes emitidos y recibidos, concretamente entre el 50 y el $70 \%$, poseen naturaleza no verbal y, además, visual (Martínez Selva, 1994). Este tipo de afirmaciones justifica que los investigadores indaguen en las claves de la recepción del mensaje; esto es, en estudiar qué porcentaje de relevancia asumen la comunicación verbal, paraverbal y no verbal cuando un individuo descifra un mensaje. Desde un perfil práctico, estos resultados pueden -es más, deben-ser interiorizados por el orador a la hora de cifrar cualquier mensaje, con la finalidad de encauzar conscientemente sus esfuerzos para que el discurso cause los efectos que él desea.

\section{CUESTIONES SOBRE RETÓRICA Y ORATORIA}

Conviene comenzar este epígrafe arrojando luz sobre la extendida confusión léxico-semántica existente entre los términos oratoria y retórica; sobre dicha cuestión, Dueñas Sanz, Fernández Fernández y Vela Valldecabres (2010) señalan:

La oratoria es la materialización de la capacidad persuasiva presentada por la retórica y se concreta como un género literario específico, por ejemplo, en discursos, conferencias o sermones. En pocas palabras, se denomina oratoria al arte de hablar con elocuencia. Ahora bien, se puede hablar bien de muchas maneras: la técnica que enseña a hablar bien es la retórica, y la oratoria es el arte de ponerlas en práctica [...] La retórica es la teoría, la oratoria la aplicación de la teoría retórica en un discurso concreto. Por eso, la retórica y la oratoria no pueden separarse y han dado lugar a ciertos malentendidos terminológicos: hablar de teoría oratoria es hablar de retórica; en cambio, hablar de práctica retórica es hablar de oratoria. Así, la retórica nace de la praxis oratoria y la oratoria se enriquece con las aportaciones de la retórica (p. 11).

Los estudios tradicionales sobre retórica y oratoria han estado monopolizados por la descripción minuciosa de la comunicación verbal, ubicando a un segundo plano -e incluso en determinados casos olvidando- la comunicación paraverbal y la comunicación no verbal. Una tendencia muy usual

1 El empleo de letras cursivas en todas las citas de este artículo constituye un fiel reflejo de la tipografía empleada en la investigación original. 
ha sido vertebrar las pesquisas en función de las cinco fases de elaboración del discurso: invención, disposición, elocución, memoria y acción; tal es el caso de los conocidos manuales de Albaladejo (1990) o Morales (2007). En estos estudios la argumentación suele constituir el punto de referencia; en concreto, indagan en los tipos de argumentos como estrategia para crear un discurso persuasivo.

En Pérez García (2014), a partir de Lo Cascio (1998), se exponen los argumentos más frecuentes, a saber: (1) argumentum ad personam: promueve la falta de veracidad del individuo que ha emitido tal aseveración; (2) argumentum ad hominem: se ataca e incluso se descalifica al individuo; (3) argumentum ad verecundiam: argumentos inconsistentes de falsa autoridad; (4) argumentum ad baculum: mediante el miedo a las consecuencias negativas en caso de no admitirlo, se considera cierto un argumento que es falso; (5) argumentum ad misericordiam: mentira que persigue la comprensión para la aprobación del argumento; (6) argumentum ad populum: toma como base la opinión generalizada de la población; (7) argumentum ad consequentiam: argumento establecido sobre las posibles consecuencias, no en la realidad de los hechos; (8) argumentum ad ignorantiam: dado que no hay una prueba que demuestre lo contrario, se defiende la falsedad de un argumento; (9) petitio principii: argumentos cuya validez se da por demostrada dado que se presentan falsamente como axiomas; (10) ignoratio elenchi: con un cambio de tema, se evade una pregunta o la tesis del oponente mediante el desarrollo de datos innecesarios; (11) post hoc ergo propter hoc: se establece una inexistente relación de causa-efecto; y (12) non sequitur: cuando las premisas no permiten deducir la conclusión.

Como es lógico, las argumentaciones pueden contener defectos: (1) falso: dado que se trata de una mentira; (2) vulgar: si se concluyen sobre él otros razonamientos distintos tras conseguirse su aceptación; (3) común: permite probar las conclusiones, ya sean las propias o las de la otra parte; (4) liviano: con una ligera excusa se trata de justificar una acción grave; (5) remoto: premisas muy generales con vastos objetivos; (6) mala definición: error surgido al definirse el todo en lugar de una parte o bien el grupo en lugar de una persona; (7) controvertible o perspicuo: cuando el argumento es innecesario, dudoso o incluso demuestra una cuestión que no había suscitado polémica; (8) no concedido: aún estando en debate, se da por probada determinada cuestión; (9) ofensivo: cuando el ánimo del auditorio puede verse herido; (10) contrario: resulta una crítica a las acciones de los receptores; y (11) inconstante: demuestra un aspecto diferente en cuanto a lo que se había establecido antes (Jiménez Leube, 1997).

Desde otro ángulo, se ha de señalar que el gran error cometido por los trabajos sobre comunicación y lenguaje es no haber observado la indivisibilidad existente en la tricotomía palabraparalenguaje-kinésica (Poyatos, 1994). Efectivamente, las publicaciones iniciales sobre retórica y oratoria no solo analizaban estos niveles de manera aislada, sino que centraban su estudio en la comunicación verbal. Los trabajos más actuales parten de tal premisa e invierten la prelación de prioridades, de forma que el análisis de la comunicación paraverbal y no verbal suele gozar de mayor protagonismo que la comunicación verbal; como se demostrará más adelante con datos cuantitativos, este cambio de rumbo se erige al constatar la mayor relevancia de la voz y el lenguaje corporal en detrimento de las palabras en el proceso de transmisión del mensaje. 
Bastantes investigaciones instruyen en los planos de la comunicación que no son meramente verbales y ponen el punto de mira en que la comunicación paraverbal y no verbal se suele cifrar y descifrar de manera inconsciente. Teniendo en cuenta que en la comunicación los elementos no verbales son emitidos de forma involuntaria, resulta muy complejo mentir empleando el lenguaje del cuerpo, y esto mismo ocurre con su desciframiento, el cual es captado y procesado de manera inconsciente; aparte, para una correcta praxis, se han de analizar e interpretar en conjunto -no de manera aisladalos indicadores no verbales (Ballenato Prieto, 2013a). El mensaje es transmitido con todo el cuerpo, de forma que el orador proyecta energía, vida y fuerza; el énfasis del discurso se sustenta en la voz, los gestos y los movimientos, por lo que se puede afirmar que «El cuerpo tiene su propio lenguaje» (Ballenato Prieto, 2013b: 187). En concreto, Azauste y Casas (2015) advierten de que para reforzar la modulación de la voz se necesita controlar el movimiento del cuerpo y especialmente la expresión facial. En este sentido, se ha de incidir en el manejo de la mirada, pues autores como Morales (2007) arguyen que representa la principal fuente de comunicación del cuerpo humano, ubicándola casi al mismo nivel que las palabras.

La correcta utilización de la pausa manifiesta el buen dominio de la oratoria que posee el sujeto que la emplea de manera acertada. Este recurso no debe ser interpretado como ausencia de comunicación, sino como una reflexión sobre las posibilidades del lenguaje (Mortara, 1991). El empleo de pausas y silencios en el discurso permite, por un lado, captar la atención, y, por el otro, controlar el ritmo del discurso. Igualmente, se ha de advertir sobre la longitud adecuada de la pausa, porque, si es lacónica, puede ser interpretada por el receptor como una interrupción, pero, si resulta excesivamente larga, puede crear intranquilidad (Martínez Selva, 1994). Por su parte, Morales (2007) propone sustituir las muletillas por pausas, de tal manera que el discurso se optimizaría en certeza, credibilidad y significación. Así pues, se puede entender que el dominio de los silencios muestra fortaleza -jamás debilidad-, como consecuencia de que se necesita jugar con el silencio al interpretar que la ausencia de pausas delata nerviosismo (Dueñas Sanz et al., 2010).

\section{COMUNICACIÓN VERBAL, PARAVERBAL Y NO VERBAL: SU RELEVANCIA EN LA TRANSMISIÓN DEL MENSAJE}

Una cuestión que ha supuesto un polémico debate en torno a la transmisión del mensaje ha sido precisamente la distribución que se le otorga a los distintos subtipos de comunicación. La alusión que efectúa Leith (2012) a propósito de la lectura de Retórica de Aristóteles evoca que el filósofo helénico se percató de la mayor relevancia de la acción frente a la elocución o el contenido del discurso. En la misma línea -aunque con un posicionamiento más firme- se sitúa Demóstenes, por su insistencia en que el primer, el segundo y el tercer factor más importante de la oratoria lo conformaba justamente la acción (Hernández \& García, 2008). Por ende, estos autores clásicos señalaban el indiscutible papel de la pronunciación del discurso; en dicho proceso, aparte de la comunicación verbal, entran en juego también la comunicación paraverbal y la no verbal.

Desde el enfoque de los componentes conductuales, van-der Hofstadt (2005) ofrece una clasificación en función de su naturaleza verbal, paraverbal o no verbal. En la Tabla 1 se recoge esta información. 


\section{Tabla 1}

Los componentes conductuales según van-der Hofstadt

\begin{tabular}{|c|c|c|}
\hline \multicolumn{3}{|c|}{ COMPONENTES CONDUCTUALES } \\
\hline Componentes verbales & Componentes paraverbales & Componentes no verbales \\
\hline $\begin{array}{l}\text { - } \text { - } \text { - Humtenido } \\
\text { - Atención personal } \\
\text { - Preguntas } \\
\text { - Respuestas a preguntas }\end{array}$ & $\begin{array}{l}\text { - Volumen de la voz } \\
\text { - Tono } \\
\text { - Timbre } \\
\text { - Fluidez verbal } \\
\text { - Velocidad } \\
\text { - Claridad } \\
\text { - Tiempo de habla } \\
\text { - Pausas/Silencios }\end{array}$ & $\begin{array}{l}\text { - Expresión facial } \\
\text { - Mirada } \\
\text { - Sonrisas } \\
\text { - Postura } \\
\text { - Orientación } \\
\text { - Distancia/Contacto físico } \\
\text { - Gestos } \\
\text { - Apariencia personal } \\
\text { - Automanipulaciones } \\
\text { - Movimientos nerviosos con manos y piernas }\end{array}$ \\
\hline
\end{tabular}

Nota: Adaptado de El libro de las habilidades de comunicación (pp. 21-35) por C. J. van-der Hofstadt, 2005, Madrid: Díaz de Santos. Copyright 2005 por Carlos J. van-der Hofstatd Román.

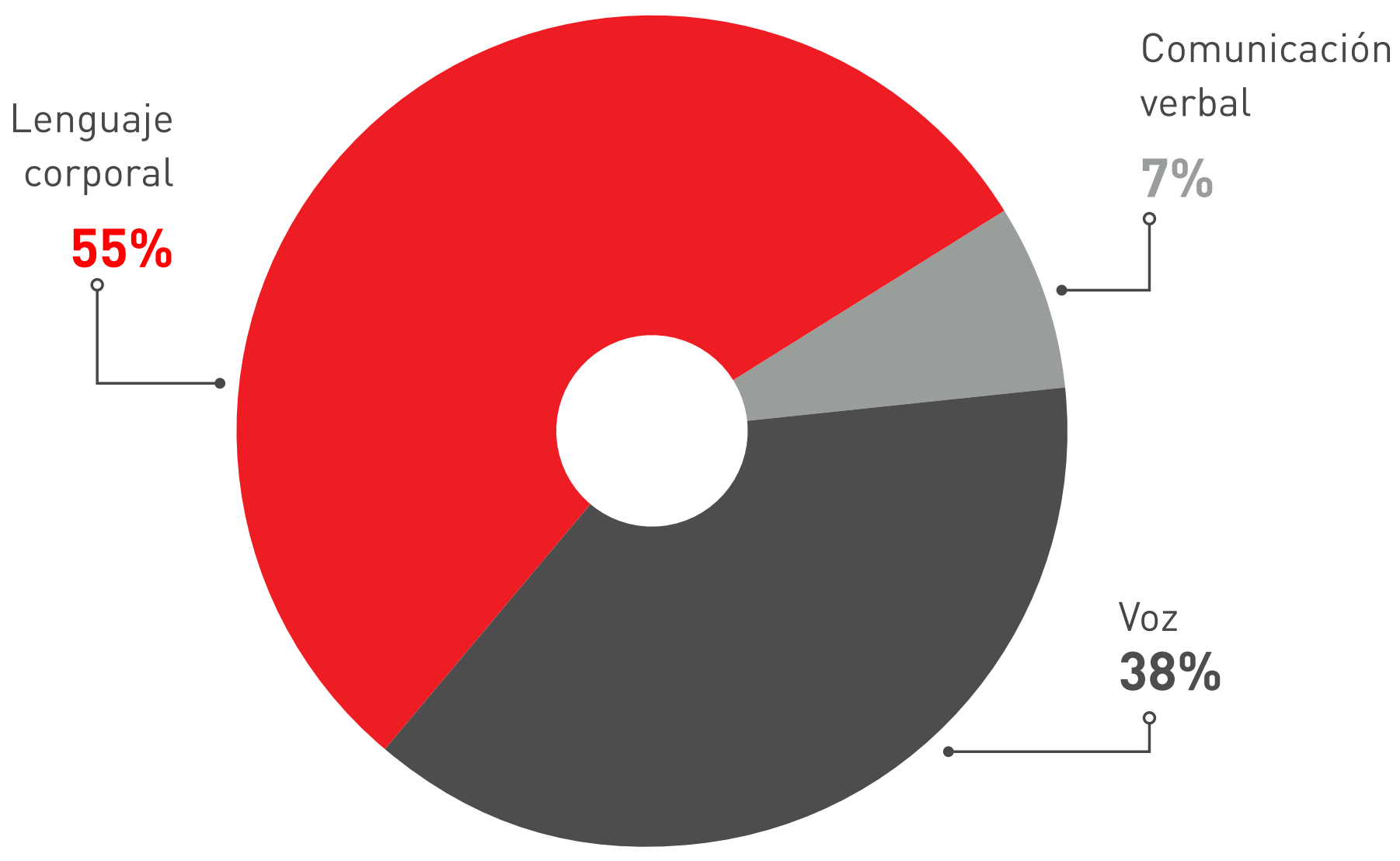

Figura 1. Datos cuantitativos de comunicación verbal, voz y lenguaje corporal según Mehrabian (1972). 


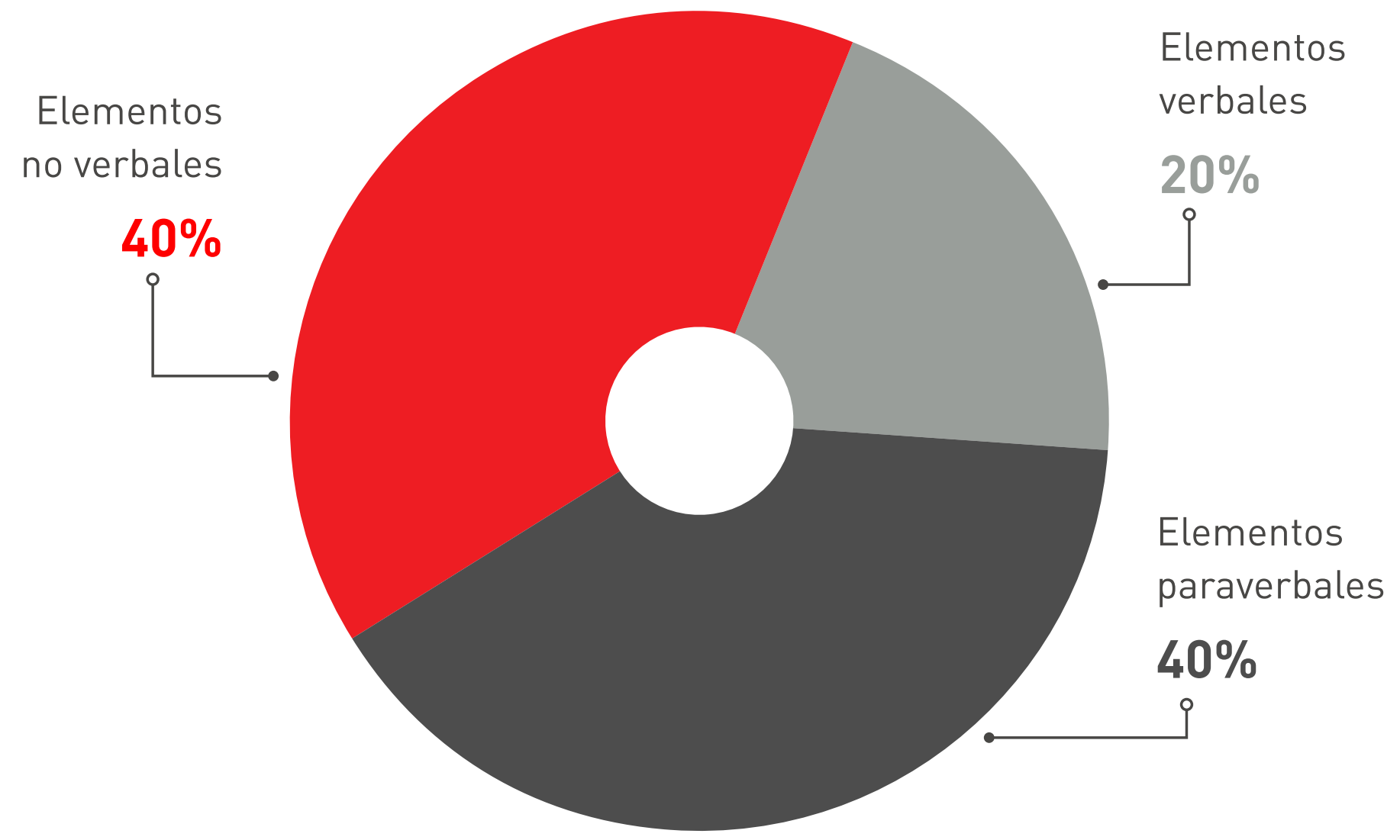

Figura 2. Datos cuantitativos de elementos verbales, elementos paraverbales y elementos no verbales según van-der Hofstadt (2005, p. 20).

El enfoque tradicional se ha caracterizado por ser un firme defensor de que estos tres subtipos de comunicación poseen un peso equitativo en la transmisión del mensaje, de tal manera que a los tres les ha asignado un salomónico $33.33 \%$. Sin embargo, tras efectuar diversos experimentos científicos, desde el campo de la piscología social en la UCLA, Mehrabian (1972, ver Figura 1) distribuye los porcentajes de manera bastante dispar: para la comunicación verbal destina únicamente el $7 \%$, a la voz le otorga un $38 \%$ (por tanto, no difiere mucho con respecto al enfoque tradicional) y al lenguaje corporal le asigna el $55 \%$ restante; como se puede observar, en esta nueva repartición se minimiza la comunicación verbal al tiempo que se maximiza la comunicación no verbal:

En el siglo XXI, desde el enfoque de la comunicación, en van-der Hofstadt (2005, ver Figura 2) se ofrece una distribución ligeramente diferente. Como en el caso de Meharabian (1972), las divergencias halladas en la comunicación paraverbal resultan nimias; por tanto, las mayores discrepancias se sitúan en los elementos verbales y no verbales, aportando una horquilla de oscilación en los elementos verbales y los paraverbales. En concreto, las cifras proporcionadas son para los elementos verbales el $20 \%$ (10\%), para los elementos paraverbales el $40 \%$ (50\%) y para los elementos no verbales el $40 \%$.

Cuatro años más tarde, a la comunicación verbal se le asigna el 20 \% en el trabajo de Orzáiz (2009); en consecuencia, el 80 \% restante compete a la capacidad informativa que se comunica a través tanto de la comunicación paraverbal -entonación, vocalización y pausas-como de la no verbal -gestos, posturas y mirada-, si bien no establece un porcentaje concreto para cada una de estas subtipologías comunicativas. 
En función de lo expuesto anteriormente, el objetivo del presente estudio es analizar tanto desde el punto de vista cuantitativo como cualitativo la relevancia que asumen la comunicación verbal, la comunicación paraverbal y la comunicación no verbal en la transmisión de un mensaje; esto es, la manera en que el receptor (un grupo de estudiantes universitarios) recibe el mensaje cifrado por el orador.

\section{MÉTODO \\ Diseño \\ Con miras a alcanzar el objetivo descrito en el párrafo precedente, se ideó una metodología basada en la observación del discurso de un orador. Los sujetos que conforman el grupo de alumnos del curso visionaron por medio audiovisual un discurso oficial de un orador conocido² de 11 minutos de duración.}

\section{Contexto}

El corpus analizado en esta investigación fue recogido en el curso denominado El poder de la palabra hablada: Cómo crear un discurso congruente mediante distintas técnicas, impartido en la Universidad de Murcia desde el 4 al 8 de mayo de 2015, con motivo de nuestra participación en el citado encuentro. En dicha ponencia, con el título "Entre el plano escrito y el oral: el complejo entramado de la comunicación", se empleó una metodología inductiva de carácter participativo, y se recopiló el corpus aquí examinado.

\section{Participantes}

En total el curso tuvo treinta alumnos, de los cuales había 18 mujeres y 12 hombres. El requisito para poder inscribirse consistía en ser miembro de la Universidad de Murcia. Si bien es cierto que la mayoría era alumnado principalmente de la Facultad de Letras, también se contó con algún caso aislado de profesorado y de personal de administración y servicios.

\section{Instrumentos de recolección de datos}

Se les pidió a los discentes que crearan grupos de trabajo unipersonales o, preferentemente, de dos 0 tres miembros. Cada grupo -finalmente se formaron 13- debía escribir de manera esquemática, con miras a que facilitara el análisis cualitativo, los déficits comunicativos que encontraban en el orador, para lo cual no se facilitó ningún tipo de plantilla o esquema, sino que se buscaba la originalidad de los alumnos. Del mismo modo, se les informó de las intenciones de realizar una investigación con los datos obtenidos, por lo que se insistió en que sus anotaciones carecieran de datos identificativos personales.

\section{Procedimiento}

Entre los 13 grupos aportaron un total de 133 comentarios. No se marcaron límites en cuanto al número de aportaciones que debían hacer. Con respecto al tiempo destinado para efectuar esta tarea, se acotó a 5 minutos. Así mismo, conviene aclarar que en esta fase los estudiantes no habían recibido en dicha sesión ningún tipo de explicación teórica.

Una vez que los grupos habían escrito sus aportaciones, se procedió a explicar de manera pormenorizada cómo en la transmisión de un mensaje existen tres fuentes de información: comunicación 
verbal, comunicación paraverbal y comunicación no verbal; a la vez que se hizo hincapié en describir las características de tales subtipologías comunicativas, puesto que previamente se habían observado algunas confusiones en los estudiantes sobre todo entre las competencias propias de la comunicación paraverbal y la no verbal.

A continuación se fomentó la reflexión sobre el porcentaje que cada subtipología de comunicación asume en las interacciones, lo cual fue sustentado en investigaciones previas mediante una metodología inclusiva en la que constantemente se invitaba a los grupos a que participaran en la conversación. No se estableció un orden, sino que los temas fueron introducidos por los grupos hilados en la conversación. Los discentes solían argumentar sus impresiones basándose en casos concretos, como es el discurso visionado en esa sesión o bien haciendo referencia a otros personajes públicos. Si bien en un principio al alumnado le costó asumir la escasa relevancia de la comunicación verbal, posteriormente se mostró más conforme con tal aseveración al percatarse de que ellos mismos precisamente habían prestado poca atención a esta subtipología comunicativa.

\section{RESULTADOS}

Como se indica anteriormente, se crearon 13 grupos de trabajo y estos aportaron un total de 133 comentarios. Por la naturaleza de esta investigación se han clasificado los comentarios en función de la temática tratada: comunicación verbal, comunicación paraverbal y comunicación no verbal. En la Tabla 2 se especifican los datos numéricos correspondientes a cada grupo en frecuencia absoluta.

\section{Tabla 2}

Datos de la frecuencia absoluta de los déficits comunicativos identificados según grupos de trabajo

$\begin{array}{lccccccc} & \text { Grupo } & \text { Grupo } & \text { Grupo } & \text { Grupo } & \text { Grupo } & \text { Grupo } & \text { Grupo } \\ & 1 & 2 & 3 & 4 & 5 & 6 & 7 \\ \text { Comunicación verbal } & 0 & 1 & 0 & 0 & 2 & 3 & 1 \\ \text { Comunicación paraverbal } & 4 & 6 & 2 & 5 & 2 & 4 & 4 \\ \text { Comunicación no verbal } & 7 & 5 & 1 & 6 & 6 & 10 & 6 \\ & \text { Grupo } & \text { Grupo } & \text { Grupo } & \text { Grupo } & \text { Grupo } & \text { Grupo } & \text { Total } \\ \text { Comunicación verbal } & 8 & 9 & 10 & 11 & 12 & 13 & \\ \text { Comunicación paraverbal } & 2 & 1 & 0 & 0 & 3 & 2 & 15 \\ \text { Comunicación no verbal } & 1 & 0 & 1 & 3 & 6 & 3 & 41 \\ \end{array}$


En la Figura 3 se comprueba de manera visual que la comunicación no verbal asume el mayor peso en la transmisión de un mensaje, frente a cifras menores de comunicación paraverbal y comunicación no verbal. Estos datos indican que la comunicación verbal tan solo suma 15 aportaciones, por lo que representa el $11.27 \%$ del corpus analizado. En segundo lugar, siguiendo una nómina de clímax ascendente, se ubican los 41 comentarios cuya temática aborda la comunicación paraverbal con el 30.82 \%. En última posición se halla la comunicación no verbal, cuya frecuencia absoluta llega a 77 y la frecuencia porcentual supone el $57.89 \%$.

A estas alturas, conviene contrastar los datos conseguidos en esta investigación con estudios precedentes. Por la similitud temática se han seleccionado Mehrabian (1972), van-der Hofstadt (2005) y Orzáiz (2009). En la Tabla 3 quedan plasmadas las divergencias porcentuales que estos autores atribuyen a los diferentes subtipos de comunicación, así como los resultados alcanzados en el presente artículo.

Contrastando estos resultados con los obtenidos en Mehrabian (1972), se aprecia que en la comunicación no verbal apenas hay diferencias: 57.89 \% en esta investigación y $55 \%$ en Mehrabian (1972). Las mayores discrepancias se encuentran, de una parte, en la comunicación paraverbal, que para Mehrabian (1972) supone el $38 \%$ y en este estudio desciende a un $30.82 \%$; de otra parte, en la comunicación verbal, que en el estudio de Mehrabian (1972) solo suma el $7 \%$ y en el actual el $11.27 \%$.

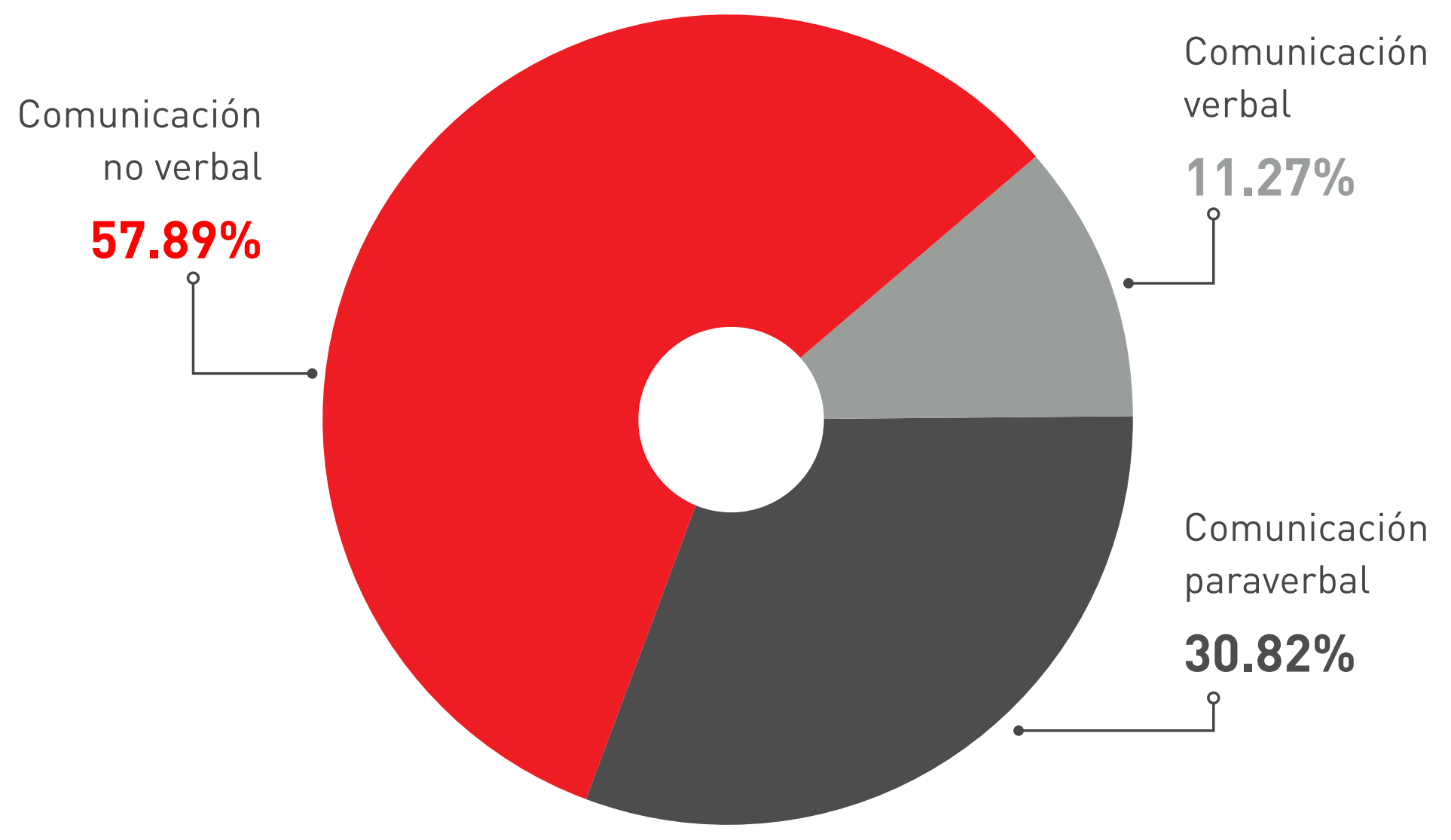

Figura 3. Datos cuantitativos globales del corpus analizado. 


\section{Tabla 3}

Comparaciones porcentuales de los tres componentes conductuales de la comunicación

$\begin{array}{lcccc}\text { Componentes } & \begin{array}{c}\text { Mehrabian } \\ (1972)\end{array} & \begin{array}{c}\text { van-der Hofstadt } \\ (2005)\end{array} & \begin{array}{c}\text { Orzáiz } \\ (2009)\end{array} & \begin{array}{c}\text { Presente } \\ \text { estudio }\end{array} \\ \text { Comunicación verbal } & 7 \% & 20 \%(10 \%) & 20 \% & 11.27 \% \\ \text { Comunicación paraverbal } & 38 \% & 40 \% & 80 \% & 30.82 \% \\ \text { Comunicación no verbal } & 55 \% & 40 \%(50 \%) & & 57.89 \% \\ \end{array}$

Las divergencias halladas con el trabajo de van-der Hofstadt (2005) demuestran una trayectoria diferente. En lo concerniente a la comunicación verbal, se abre una horquilla entre el 10 y el $20 \%$ en van-der Hofstadt (2005), mientras que los resultados de la presente investigación sitúan esta subtipología en el $11.27 \%$. La comunicación paraverbal difiere en 10 puntos, pues en van-der Hofstadt (2005) asume el $40 \%$ y en este estudio el $30.82 \%$. En una línea similar, la comunicación no verbal para van-der Hofstadt (2005) representa una horquilla que oscila entre el 40 y el $50 \%$, mientras que en esta pesquisa asciende al $57.89 \%$.

Los datos estadísticos incluidos en Orzáiz (2009) pueden calificarse de menos precisos, no solo por aportar números redondos, sino también por el hecho de no desglosar los porcentajes correspondientes a la comunicación paraverbal y no verbal. La diferencia porcentual entre estas cifras y las alcanzadas en el corpus aquí examinado dista casi 9 puntos. Concretamente, para Orzáiz (2009) la comunicación verbal adquiere el $20 \%$, mientras que en el presente corpus representa el $11.27 \%$. Con respecto a la suma de la comunicación paraverbal y la no verbal, en Orzáiz (2009) obtiene el 80 \% y en este análisis se sitúa en un $88.71 \%$.

A continuación se procede al análisis cualitativo del corpus. Por este motivo se presenta una selección de comentarios aportados por los alumnos agrupados en función de la subtipología comunicativa aludida.

Como se puede comprobar en la Tabla 4, las observaciones sobre la comunicación verbal ponen el punto de mira en la longitud de la frase, en el desorden temático, en la cita de autores que al ser tan reiterada resulta confusa e incluso en la falta de coherencia en los asuntos tratados. Una cuestión reseñable de los comentarios relacionados con la comunicación verbal se centra, precisamente, en el hecho de que no exista ninguna aportación (de las 15 que hay) que dé datos concretos sobre el discurso utilizado; tan solo se observa un comentario que aborda el uso de las figuras retóricas: «Verborrea y uso excesivo de las figuras retóricas. Justificable por tener de público a gente de un nivel cultural elevado» (grupo 6). 
Tabla 4

Selección de aportaciones sobre comunicación verbal

\section{Comunicación verbal}

- Frases largas (grupo 2).

- Desorden en el discurso respecto de los temas tratados (grupo 5).

- Verborrea y uso excesivo de las figuras retóricas. Justificable por tener de público a gente de un nivel cultural elevado (grupo 6).

- Cita demasiado a otros autores, de manera que a veces no sabes cuándo habla él y cuándo está citando textos de otros (grupo 7).

- Da saltos temáticos entre párrafos (grupo 12).

\section{Tabla 5}

Selección de aportaciones sobre comunicación paraverbal

\section{Comunicación paraverbal}

- Tono de voz: no hay cambios en el tono, lo hace soporífero (grupo 1).

- No existen cambios en el tono de la voz. Los cambios de tono ayudarían a captar la atención (grupo 2).

- No existen pausas entre las diferentes partes del discurso (grupo 2).

- Discurso no fluido (lenguaje paraverbal) (grupo 4).

- Mejorar la modulación de la voz y la entonación (grupo 4).

- Velocidad. Varía mucho en la lectura (grupo 4).

- Algo de repetibilidad y tartamudeo (grupo 5).

- Muy sonoras las “s” (grupo 6).

- No modula la voz (grupo 7).

- No cambia casi el tono de voz, haciendo el discurso monótono y aburrido (grupo 8).

- Voz débil, entrecortada (grupo 11).

- Modulación de la voz sin entonación ninguna, mantiene el mismo tono (grupo 11).

- No tiene cambios de entonación, es muy plano y monótono (grupo 12).

- Le tiembla la voz (grupo 12).

- Muy monótono en su entonación (grupo 13)

Sobre la comunicación paraverbal (ver Tabla 5), las aportaciones tratan fundamentalmente los déficits existentes en la modulación y la entonación de la voz, siendo en algunos casos críticas algo severas: «Tono de voz: no hay cambios en el tono, lo hace soporífero» (grupo 1) o «No cambia casi el tono de voz, haciendo el discurso monótono y aburrido» (grupo 8). Otras cuestiones que destacan son la falta de pausas («No existen pausas entre las diferentes partes del discurso» [grupo 2]), los cambios de velocidad («Velocidad. Varía mucho en la lectura» [grupo 4]), los problemas en la voz por tartamudeo [«Algo de repetibilidad y tartamudeo» [grupo 5]), la debilidad («Voz débil, entrecortada» [grupo 11]) 0 los temblores («Le tiembla la voz» [grupo 12]). Destaca un comentario por su concreción en el nivel fónico a la hora de pronunciar este alófono alveolar: «Muy sonoras las “s"» (grupo 6). 
Las contribuciones vinculadas con la comunicación no verbal (ver Tabla 6) se refieren, sobre todo, a la carencia de movimiento corporal y a la actitud del orador por mostrarse como un lector. Dentro de estas críticas dirigidas a la falta de movimientos se formulan observaciones sobre los brazos [«Escasa movilidad de los brazos y manos, quizá esto ayudaría a enfatizar el discurso» [grupo 2]), las manos («Manos en los bolsillos» [grupo 6]), los gestos faciales («lmpasible, sin gesticular» [grupo 13]) e incluso la mirada («Solo mira a un punto del auditorio, no al resto» [grupo 12]). Del mismo modo, constituye objeto de crítica la actitud adoptada al leer el discurso: «Es un lector, no un orador» (grupo 1), «Cohibido» (grupo 4) o «Seriedad» (grupo 9). También se encuentran aportaciones relacionadas con la desacertada vestimenta del orador: «Traje mal entallado. Colores sobrios» (grupo 6) y «El tono del traje no le favorece al orador y no resalta con el fondo de la sala» (grupo 13). Igualmente, el mobiliario también aparece en la nómina de aspectos mejorables: «El atril está demasiado alto» (grupo 13).

\section{Tabla 6}

Selección de aportaciones sobre comunicación no verbal

\section{Comunicación no verbal}

- Estático: no mueve el torso, apenas las manos (grupo 1).

- Expresión facial: alaba e insulta con la misma expresión facial. No expresa sentimientos positivos ni negativos (grupo 1).

- Falta de contacto visual debido a que lee el discurso (grupo 2).

- Escasa movilidad de los brazos y manos, quizá esto ayudaría a enfatizar el discurso (grupo 2).

- Falta de gesticulación (grupo 2).

- Cohibido (grupo 4).

- Mirada baja (grupo 4).

- Casi en todo momento sujeta el papel (grupo 5).

- Le falta expresión facial (grupo 5).

- Manos en los bolsillos (grupo 6).

- Postura no erguida. Transmite poca seguridad (grupo 6).

- Al no saberse bien el discurso, mira abajo muy a menudo dando una sensación poco profesional (grupo 6).

- No usa el juego de miradas para hacer sentir al público partícipe del discurso, creando una pequeña barrera (grupo 6).

- Traje mal entallado. Colores sobrios (grupo 6).

- Postura estática (grupo 7).

- Apenas se dirige al público (grupo 7).

- Seriedad (grupo 9).

- Uso de comillas con los dedos sin introducir citas (grupo 10).

- Mira de soslayo a sus interlocutores (grupo 10).

- Inmovilidad total, aun poniendo énfasis en algunas frases con gestos de brazos (grupo 11).

- Solo mira a un punto del auditorio, no al resto (grupo 12).

- No levanta la cabeza del papel, apenas mira, la voz la dirige al atril (grupo 12).

- Impasible, sin gesticular (grupo 13).

- Mira más a la derecha por estar sentado en ese lugar la máxima autoridad (grupo 13).

- El tono del traje no le favorece al orador y no resalta con el fondo de la sala (grupo 13).

- El atril está demasiado alto (grupo 13).

- No hace ningún gesto (grupo 13).

- No está erguido (grupo 13). 


\section{DISCUSIÓN}

Desde tiempos remotos el hombre se percató del relevante papel que desempeña la oratoria a la hora no solo de persuadir al receptor con fines utilitaristas, sino también -qué duda cabe- contribuye a la proyección de la buena imagen del emisor. Ambas cuestiones atañen tanto a contextos públicos (tal es el caso de los entornos laborales) como privados (como pueden ser las relaciones con familiares y amigos); esto es, la comunicación eficaz compete a todas las facetas de los seres humanos. Aunque la eclosión de investigaciones de esta índole resulta bastante reciente como consecuencia del despertar del interés por el discurso, desde antaño se documentan escritos dedicados al estudio sobre todo de la retórica.

Si bien las primeras investigaciones de retórica y oratoria versaban principalmente sobre la comunicación verbal y relegaban a un segundo plano la comunicación paraverbal y la no verbal, en los estudios más recientes se ha invertido el foco de interés, debido a la constatación de la relevancia que tienen los distintos subtipos de comunicación en la percepción del mensaje. Por tanto, los primeros estudios basados fundamentalmente en la elaboración del discurso y en la invención de los argumentos han dado paso a investigaciones que abordan el tema de la ejecución del discurso, en las cuales el paralenguaje y la comunicación no verbal son analizados pormenorizadamente. Ya en la década de los 70 del pasado siglo, mediante experimentos científicos, en Mehrabian (1972) se ratificó la prevalencia de la comunicación no verbal y paraverbal frente a la verbal.

Los datos obtenidos en el corpus analizado en el presente artículo señalan que el $57.89 \%$ de los comentarios escritos por los alumnos sobre los déficits comunicativos hallados en el discurso visionado se vinculan con aspectos concernientes a la comunicación no verbal, el 30.82 \% con la comunicación paraverbal y tan solo el $11.27 \%$ con la comunicación puramente verbal. Por ende, son resultados que se asemejan, grosso modo, a los obtenidos por Mehrabian (1972), si bien difieren parcialmente de los establecidos por van-der Hofstadt (2005) en comunicación paraverbal y comunicación no verbal, existiendo similitudes en la comunicación verbal, y discrepan de los aportados en Orzáiz (2009).

A la luz de estos resultados, se pone de manifiesto la urgente necesidad de tener en cuenta tales aspectos al momento no solo de emitir un discurso, sino que también el receptor ha de ser consciente de cómo interpreta el mensaje. Asumir esta información convierte al sujeto en un ser con mayor eficiencia desde el punto comunicativo y, simultáneamente, más difícil de manipular, dado que posee conocimiento de las estrategias comunicativas relacionadas con la persuasión. En la sociedad actual cualquier individuo está inmerso en un proceso de comunicación casi continuo, en el que está emitiendo y recibiendo mensajes. En consecuencia, resulta ineludible difundir el incuestionable protagonismo de la comunicación paraverbal y la no verbal para una correcta transmisión o interpretación del mensaje.

\section{Futuras líneas de investigación}

Dada la muestra tan reducida utilizada en este estudio (133 comentarios en total), se necesitan investigaciones con una orientación similar que arrojen luz desde esta perspectiva. El método seguido recoge fielmente los puntos débiles de la comunicación observados por los receptores de un discurso oral. A la par, sería conveniente valorar si se podría modificar este experimento para efectuarlo de forma 
más guiada, de tal manera que se facilite una nómina de los elementos que componen la comunicación verbal, paraverbal y no verbal para que el alumno simplemente se limite a señalar los elementos de esa lista que el orador no ejecuta de manera correcta. Evidentemente, este tipo de corpus tan solo permitiría un análisis de perfil cuantitativo y, además, no refleja de manera fidedigna las impresiones del receptor, dado que al leer la lista de elementos se va modificando su interpretación.

Quizá sería conveniente llevar a cabo un estudio análogo, pero más pormenorizado, estructurándolo en tres fases; en concreto, en la primera fase se seguiría el patrón aquí utilizado (visionar un discurso a través de un medio audiovisual), en una segunda fase el mismo discurso se reproduce a los discentes solo a través de audio (no vídeo), y en la tercera fase los discentes deben leer el discurso. En la primera fase se ha demostrado en esta investigación que los estudiantes se centran sobre todo en la comunicación no verbal, en la segunda fase se parte de la hipótesis de que primará el paralenguaje y en la última tan solo la comunicación verbal. En esta última etapa -en la que el alumno se ha fijado realmente en el contenido de la comunicación verbal- es cuando se le invitaría a reflexionar al discente sobre los motivos por los que en la primera y segunda fase no ha puesto su foco de atención sobre la comunicación verbal.

\section{REFERENCIAS}

Albaladejo, T. (1990). Retórica. Madrid: Síntesis.

Aristóteles (2001). Retórica. Madrid: Alianza Editorial.

Azauste, A. \& Casas, J. (2015). Manual de retórica española. Barcelona: Ariel.

Ballenato Prieto, G. (2013a). Comunicación eficaz. Teoría y práctica de la comunicación humana. Madrid: Ediciones Pirámide.

Ballenato Prieto, G. (2013b). Hablar en público. Arte y técnica de la oratoria. Madrid: Ediciones Pirámide.

Berlanga, I. \& García, F. (2014). Ciberretórica: Aristóteles en las redes sociales. Madrid: Editorial Fragua.

Cattani, A. (2010). Expresarse con acierto. Una palabra para cada ocasión, una ocasión para cada palabra. Madrid: Alianza Editorial.

Dueñas Sanz, B., Fernández Fernández, E. \& Vela Valldecabres, D. (2010). De Cicerón a Obama: El arte de comunicar con eficacia. Retórica, oratoria y técnicas de expresión oral. La Coruña: Netbiblio.

Fernández García, F. (2000). Estrategas del diálogo. La interacción comunicativa en el discurso político-electoral. Granada: Colección Gipal. Hernández, J. A. \& García, M. C. (2008). El arte de hablar. Manual de retórica práctica y de oratoria moderna. Barcelona: Ariel. Jiménez Leube, J. (1997). La construcción del discurso: Notas sobre el método retórico. Madrid: Universidad Europea de Madrid. Laborda Gil, X. (2014). Inteligencia emocional. Barcelona: Plataforma Editorial.

Leith, S. (2012). ¿Me hablas a mí? La retórica de Aristóteles a Obama. Madrid: Taurus.

Martínez Selva, J. M. (1994). Guía práctica para hablar bien en público y comunicarse eficazmente. Murcia: Dostovat Internacional. Mehrabian, A. (1972). Nonverbal Communication. Chicago: Adeline-Atherton.

Morales, C. (2007). Guía para hablar en público. Método completo y práctico para las más diversas situaciones. Madrid: Alianza Editorial. Mortara, B. (1991). Manual de retórica. Madrid: Cátedra.

Orzáiz, O. (2009). Comunicación no verbal y paraverbal en el debate político entre Zapatero y Rajoy. Tonos Digital, 18. Recuperado de https:// goo.gl/M4mQrn 
Pérez García, E. (2014). Deixis social y (des)cortesía verbal como estrategias argumentativas. Análisis discursivo del debate político desde un enfoque sociopragmático (Tesis doctoral). Recuperada de https://goo.gl/xvWmve

Poyatos, F. (1994). La comunicación no verbal. I. Cultura, lenguaje y conversación. Madrid: Istmo.

van-der Hofstadt, C. (2005). El libro de las habilidades de comunicación (2ª ed.). Madrid: Ediciones Díaz de Santos.

\section{AGRADECIMIENTOS}

El corpus analizado en la presente investigación ha sido recogido en la participación en el curso El poder de la palabra hablada: Cómo crear un discurso congruente mediante distintas técnicas, celebrado en mayo de 2015 en la Universidad de Murcia. Aprovechamos la ocasión para agradecer a este encuentro científico su ofrecimiento a participar, así como a los alumnos el facilitarnos la recopilación del corpus.

(c) Los autores. Este artículo es publicado por la Revista Digital de Investigación en Docencia Universitaria del Área de Institutional Research and Effectiveness de la Dirección de Aseguramiento de la Calidad, Universidad Peruana de Ciencias Aplicadas. Este es un artículo de acceso abierto, distribuido bajo los términos de la LicenciaCreativeCommons Atribución-Compartirlgual 4.0 Internacional.I http://creativecommons.org/licenses/bysa/4.0/), que permite el uso no comercial, distribución y reproducción en cualquier medio, siempre que la obra original sea debidamente citada. 